\title{
Exploring flubendazole formulations for use in sheep. Pharmacokinetic evaluation of a cyclodextrin-based solution
}

\author{
Laura Ceballos ${ }^{1,2^{*}}$, Laura Moreno ${ }^{1,2}$, Juan J Torrado ${ }^{2,3}$, Carlos Lanusse ${ }^{1,2}$ and Luis Alvarez ${ }^{1,2}$
}

\begin{abstract}
Background: Flubendazole (FLBZ) is a poor water solubility broad-spectrum BZD methylcarbamate anthelmintic compound. Cyclodextrins (CDs) are usually used to increase aqueous solubility of poor hydrosoluble compounds. The comparative in vitro aqueous solubility of FLBZ and other BZD anthelmintics in the presence of hydroxypropyl- $\beta$-cyclodextrin (HP $\beta C D$ ) was evaluated in the current work. Additionally, the comparative pharmacokinetic behaviour of FLBZ (and its metabolites) administered by the intraruminal (i.r.) or intraabomasal (i.a.) routes to sheep as either an aqueous CDs-based solution or a conventional carboximethylcellulose (CMC) suspension was assessed. Drug solubility studies involving albendazole, mebendazole, oxfendazole and FLBZ were performed in an aqueous solution ( $\mathrm{pH} 1.2$ or 7.4$)$ with or without $\mathrm{HP} \beta C D(10 \%, w / v)$. The pharmacokinetic study involved two experiments. Experiment 1: In a crossover study, sheep received either a FLBZ-CDs solution $(n=3)$ or a FLBZ-CMC suspension $(\mathrm{n}=3)$ by the i.r. route $(3.8 \mathrm{mg} / \mathrm{kg})$. The treatment Groups were reversed after a 21-days washout period. Experiment 2: sheep $(n=4)$ were treated by the i.a. route with the FLBZ-CDs solution $(3.8 \mathrm{mg} / \mathrm{kg})$. Plasma and abomasal fluid samples were collected between 0 and $72 \mathrm{~h}$ post-treatment. Samples were analysed by HPLC.
\end{abstract}

Results: Improvement of FLBZ aqueous solubility due to CDs resulted markedly higher than that observed for mebendazole and albendazole. However, oppositely to what was expected, the absorption-related pharmacokinetic parameters did not show any marked formulation-dependant effect. After the i.a. administration of FLBZ, the AUC and the Tmax of the parent compound were significantly $(P<0.05)$ reduced, which is consistent with ruminal bypass.

Conclusion: The administration of FLBZ as a CDs-based solution, does not seem to achieve great practical relevance for parasite control in sheep.

\section{Background}

Flubendazole (FLBZ) is a broad-spectrum benzimidazole (BZD) methylcarbamate anthelmintic available for use in human and some domestic animals. It is widely used for parasite control in pigs, chicken, turkeys and game birds. FLBZ is commercially available for oral administration as a paste, tablets, pellet or premix formulations [1]. BZD anthelmintics are extensively biotransformed in all

\footnotetext{
* Correspondence: ceballos@vet.unicen.edu.ar

'Departamento de Fisiopatología, Laboratorio de Farmacología, Facultad de Ciencias Veterinarias, Universidad Nacional del Centro de la Provincia de Buenos Aires (UNCPBA), Campus Universitario, 7000 Tandil, Argentina ${ }^{2}$ Consejo Nacional de Investigaciones Científicas y Técnicas (CONICET), Tandil, Argentina

Full list of author information is available at the end of the article
}

mammalian species studied [2]. FLBZ is metabolized by microsomal and cytosolic fractions obtained from sheep liver and duodenal mucosa into a reduced FLBZ metabolite (R-FLBZ) [3]. R-FLBZ was the main analyte recovered from the bloodstream of FLBZ treated sheep [4], in which only trace amounts of the hydrolysed metabolite (H-FLBZ) were detected.

The antiparasitic activity of BZD anthelmintics largely depends on their affinity for parasite $\beta$-tubulin, the putative mode of action [5], but also on their ability to reach high and sustained concentrations at the site of parasite location; which, in turn, depends on pharmacokinetic, metabolic and tissue distribution processes in the host [6]. Despite the type of helminth involved, the higher the

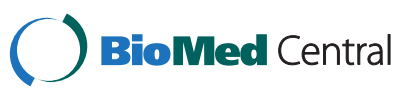


concentrations achieved at the parasite location, the higher the amount of drug reaching the target parasite [7], which is strongly supported by the findings from different in vivo studies [8-10] where systemic drug availability and efficacy were simultaneously estimated. Because the low aqueous solubility of the methylcarbamate BZD compounds, poor/erratic gastrointestinal absorption is a common inconvenient for the systemic availability of orally administered BZD in most species [6]. Consequently, enhanced systemic availability of the parent drug/active metabolite obtained by increased drug absorption will correlate with an improved antiparasitic effect.

The cyclodextrins (CDs) are cyclic oligosaccharides which are well known as molecular host capable of including water-insoluble guest molecules via noncovalent interaction within their hydrophobic cavity [11]. The CDs-drug complex formations results on changes in the physicochemical properties of the guest drug. Consequently, enhanced aqueous solubility and bioavailability of guest molecules are common effects observed after the formulation of poorly water soluble drugs with CDs [12]. The ability of CDs to enhance oral absorption of poorly water-soluble drugs has been well documented [13-16]. Furthermore, CDs enhance oral bioavailability of FDA's Class II compounds (poor aqueous solubility, high permeability) such as the BZD methylcarbamates [17]. In fact, it has been reported that hydroxypropyl- $\beta-C D(\mathrm{HP} \beta C D)$ increase the relative bioavailability of albendazole (ABZ) metabolites in sheep [18]. Furthermore, ABZ-CDs complexes enhance the bioavailability of ABZ metabolites in mice, improving its activity against Trichinella spiralis $[19,20]$.

Previous work carried out in our laboratory demonstrated that CDs enhanced the absorption and systemic availability of FLBZ in mice [21]. This modified pharmacokinetic behaviour permitted an enhanced drug exposure of the hydatid cysts which increased FLBZ clinical efficacy against cystic echinococcosis developed in mice [21]. While mice infected intraperitoneally with protoescoleces of E. granulosus develop cyst in the whole abdominal cavity, sheep naturally infected with $E$. granulosus oncospheres develop hydatid cyst in similar locations (liver, lungs, etc.) to those observed in humans. Complementary work to evaluate the efficacy of FLBZ against cystic echinococcosis developed in sheep is planned. However, before any clinical efficacy trial is performed, the effect of CDs in the pharmacokinetic behavior of FLBZ in sheep needs to be assessed. The comparative in vitro aqueous solubility of FLBZ and other closely related BZD anthelmintics in the presence of $\mathrm{HP} \beta C D$ was evaluated in the current work. Based on those solubility results, the comparative plasma and abomasal fluid pharmacokinetic behaviour of FLBZ (and its metabolites) intraruminally (i.r.) administered to sheep as either an aqueous CDs-based solution or a conventional carboxymethylcellulose (CMC) suspension was assessed. Complementary, the FLBZ/metabolites disposition kinetic was characterized after the experimental intraabomasal (true stomach in ruminants) of the FLBZ CDs-based solution.

\section{Results}

The comparative aqueous solubility of different BZD compounds assayed with or without HPßCD at $\mathrm{pH} 1.2$ and 7.4 is shown in Table 1. BZD solubility greatly increased at a $\mathrm{pH}$ value of 1.2 , in which the highest aqueous solubility $(6.6 \pm 1.3 \mathrm{mg} / \mathrm{mL})$ was observed for the most polar ABZSO metabolite. Furthermore, the presence of HPßCD significantly enhanced the solubility of the different BZD compounds at both $\mathrm{pH}$ values assayed $(\mathrm{P}<0.05)$. At $\mathrm{pH} 1.2$ (with $\mathrm{HP} B \mathrm{CD})$, the aqueous solubility resulted ABZSO > FLBZ > OFZ > ABZ > MBZ. However, the greater HPßCD-induced "solubility increasing effect" ( $\mathrm{pH}$ 1.2) was observed for FLBZ (75 fold), which resulted higher than that observed for OFZ (35 fold), MBZ (20 fold) ABZ (1.3 fold) or ABZSO (0.7 fold) (Table 1).

The comparative mean plasma concentration profiles of FLBZ (a) and R-FLBZ (b) observed after the i.r. administration of FLBZ formulated both as a CDs-solution and $\mathrm{CMC}$-suspension are shown in Figure 1. In experimental groups (FLBZ-CDs and FLBZ-CMC), the parent drug and its R-FLBZ metabolite were the main analytes

Table 1 Evaluation of the aqueous solubility $(\mu \mathrm{g} / \mathrm{mL}, \mathrm{n}=6)$ of different benzimidazole (BZD) compounds with or without hydroxypropyl-ß-cyclodextrin (HPBCD) (10\%) at different pHs (1.2 or 7.4)

\begin{tabular}{lcccc}
\hline BZD compound & \multicolumn{2}{c}{ pH 1.2 } & \multicolumn{2}{c}{ pH 7.4 } \\
\cline { 2 - 5 } & With HPBCD & Without HPBCD & With HPBCD & Without HPBCD \\
\hline Albendazole & $921.1 \pm 347.3$ & $406.1 \pm 53.4^{*}$ & $43.0 \pm 8.3$ & $4.6 \pm 1.3^{*}$ \\
\hline Albendazole sulphoxide & $6637.7 \pm 1370.2$ & $3818.6 \pm 202.1^{*}$ & $871.9 \pm 129.3$ & \\
\hline Mebendazole & $436.7 \pm 47.4$ & $20.5 \pm 5.0^{*}$ & $43.0 \pm 8.3$ & $83.6 \pm 7.6^{*}$ \\
\hline Oxfendazole & $1902.5 \pm 605.8$ & $419.7 \pm 29.2^{*}$ & $348.1 \pm 46.8$ & $4.6 \pm 1.3^{*}$ \\
\hline Flubendazole & $2251.7 \pm 551.5$ & $29.6 \pm 2.8^{*}$ & $163.8 \pm 119.7$ & $5.5 \pm 1.1^{*}$ \\
\hline
\end{tabular}

${ }^{*}$ At each $\mathrm{pH}$ value (1.2 or 7.4), significantly different from the solubility obtained in the presence of HPBCD at $\mathrm{P}<0.05$. 


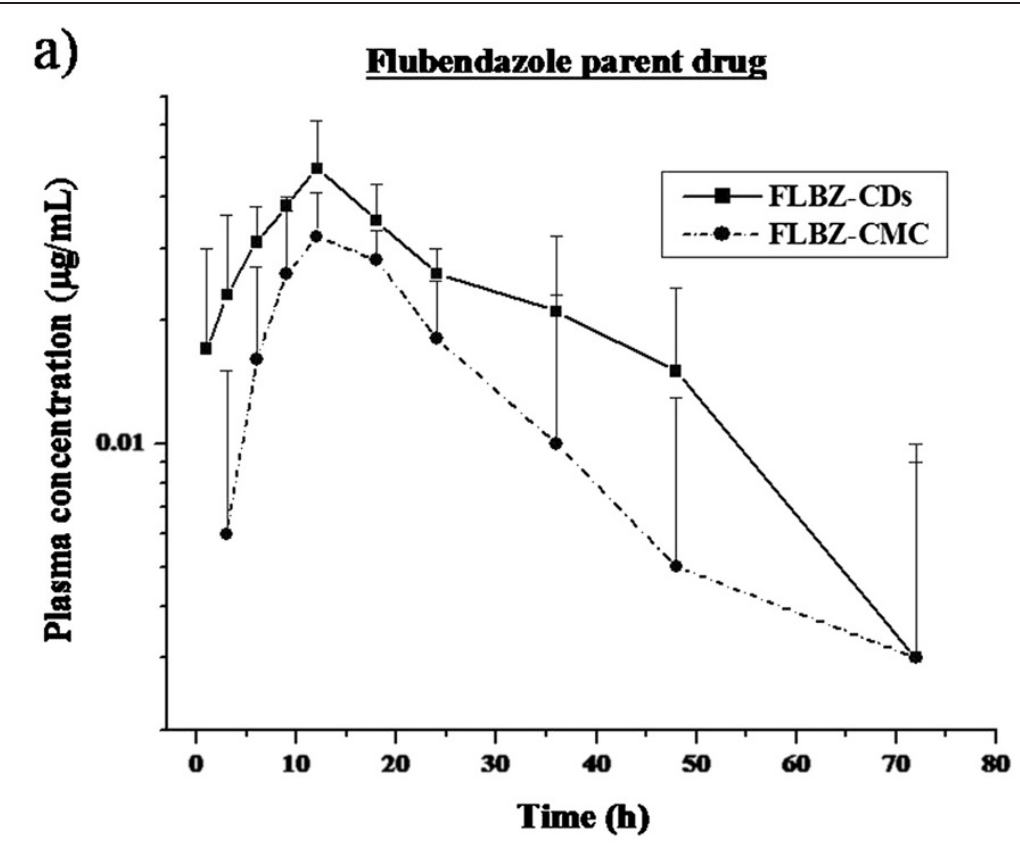

b) Reduced flubendazole metabolite

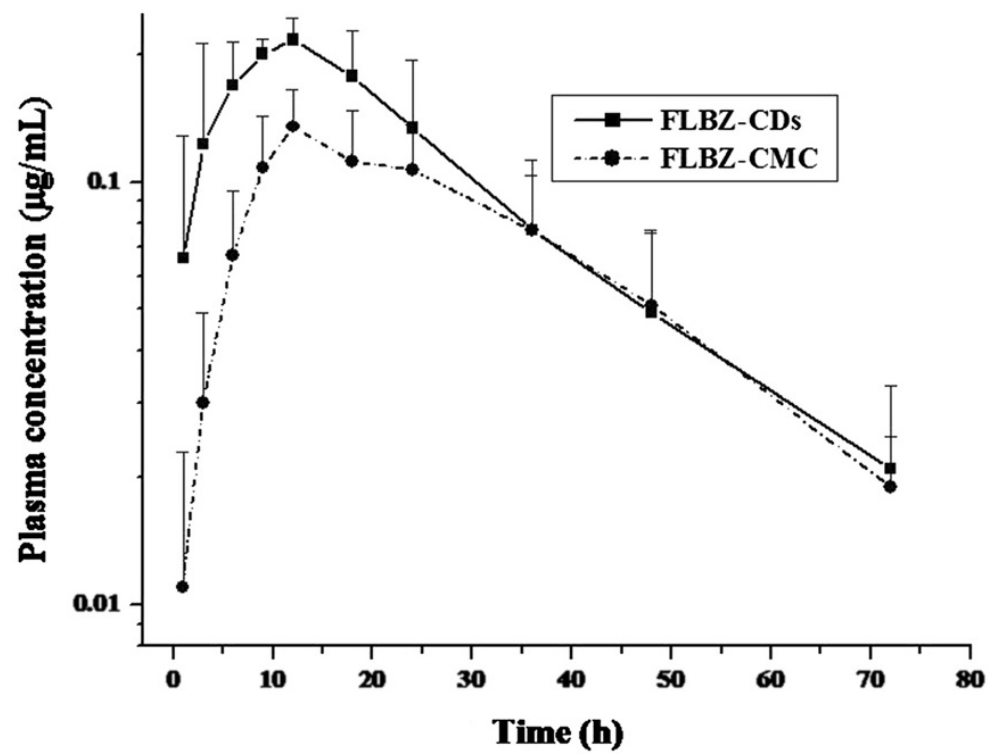

Figure $1 \mathrm{FLBZ} /$ metabolites plasma concentrations. Comparative mean $( \pm$ SD) plasma concentration profiles $(n=6)$ for $\mathbf{a})$ flubendazole $(F L B Z)$, and $\mathbf{b}$ ) reduced flubendazole (R-FLBZ), after the intraruminal (i.r.) administration of FLBZ (3.8 mg/kg) as either, a cyclodextrin (CDs) solution or a carboxymethylcellulose (CMC) suspension to sheep.

recovered in plasma. Low concentrations of the H-FLBZ metabolite were detected in plasma between 18 and $48 \mathrm{~h}$ after the administration of FLBZ in all experimental animals, which preclude any pharmacokinetic analysis. The mean pharmacokinetic parameters for FLBZ and RFLBZ after the administration of FLBZ as a CDssolution (i.r. and i.a. administration) or CMC-suspension (i.r. administration), are shown in Table 2. FLBZ AUC values were similar between formulations after its i.r. administration. Low peak plasma concentrations for the parent compound were observed after the administration of FLBZ in both CDs-solution $(0.05 \pm 0.01 \mu \mathrm{g} / \mathrm{mL})$ and CMC-suspension $(0.03 \pm 0.01 \mu \mathrm{g} / \mathrm{mL})$. However, the observed plasma Cmax value for R-FLBZ resulted significantly higher in FLBZ-CDs treated compared to that observed in the FLBZ-CMC treated animals. 
Table 2 Plasma pharmacokinetic parameters (mean \pm SD) for flubendazole (FLBZ) and its reduced metabolite (R-FLBZ), obtained after the intraruminal (i.r.) administration of FLBZ (3.8 $\mathrm{mg} / \mathrm{kg}, \mathrm{n}=6)$ formulated as a cyclodextrin-based solution (FLBZ-CDs) or a carboximethylcelullose suspension (FLBZ-CMC) to sheep (Experiment 1)

\begin{tabular}{|c|c|c|c|c|c|c|}
\hline \multirow{2}{*}{$\begin{array}{l}\text { PHARMACOKINETIC } \\
\text { PARAMETERS }\end{array}$} & \multicolumn{3}{|c|}{ FLBZ } & \multicolumn{3}{|c|}{ R-FLBZ } \\
\hline & $\begin{array}{l}\text { FLBZ-CDs }{ }^{(1)} \\
\text { i.r. treatment }\end{array}$ & $\begin{array}{l}\text { FLBZ-CMC } \\
\text { i.r. treatment }\end{array}$ & $\begin{array}{l}\text { FLBZ-CDs }{ }^{(2)} \\
\text { i.a. treatment }\end{array}$ & $\begin{array}{l}\text { FLBZ-CDs }{ }^{(1)} \\
\text { i.r. treatment }\end{array}$ & $\begin{array}{l}\text { FLBZ-CMC } \\
\text { i.r. treatment }\end{array}$ & $\begin{array}{l}\text { FLBZ-CDs }{ }^{(2)} \\
\text { i.a. treatment }\end{array}$ \\
\hline T1/2abs/for (h) & $3.67 \pm 1.57$ & $2.92 \pm 0.94$ & $0.40 \pm 1.43^{*}$ & $3.00 \pm 1.21$ & $4.95 \pm 1.72$ & $0.90 \pm 0.30^{*}$ \\
\hline Cmax $(\mu \mathrm{g} / \mathrm{mL})$ & $0.05 \pm 0.01$ & $0.03 \pm 0.01$ & $0.07 \pm 0.04^{*}$ & $0.23 \pm 0.04$ & $0.14 \pm 0.03^{*}$ & $0.35 \pm 0.09^{*}$ \\
\hline $\operatorname{Tmax}(\mathrm{h})$ & $12.0 \pm 3.79$ & $12.5 \pm 2.95$ & $2.75 \pm 2.36^{*}$ & $10.5 \pm 4.93$ & $11.5 \pm 1.22$ & $2.75 \pm 1.50^{*}$ \\
\hline $\mathrm{AUC}_{0-\mathrm{t}}(\mu \mathrm{g} \cdot \mathrm{h} / \mathrm{mL})$ & $1.35 \pm 0.34$ & $0.78 \pm 0.53$ & $0.65 \pm 0.29$ & $6.82 \pm 1.77$ & $4.92 \pm 1.46$ & $3.83 \pm 1.86^{*}$ \\
\hline $\mathrm{T} 1 / 2 \mathrm{el}(\mathrm{h})$ & $25.8 \pm 14.0$ & $19.2 \pm 15.1$ & $15.1 \pm 8.27^{*}$ & $17.0 \pm 5.19$ & $18.4 \pm 3.74$ & $6.73 \pm 3.70^{*}$ \\
\hline MRT (h) & $41.6 \pm 19.0$ & $34.5 \pm 20.3$ & $19.7 \pm 9.73^{*}$ & $28.8 \pm 8.58$ & $35.4 \pm 3.90$ & $10.8 \pm 4.07^{*}$ \\
\hline
\end{tabular}

The pharmacokinetic parameters obtained after the intra-abomasal (i.a.) administration of FLBZ (3.8 mg/kg, $\mathrm{n}=4$ ) formulated as a cyclodextrin-based solution (FLBZ-CDs), is also shown (Experiment 2). T1/2abs/for: FLBZ absorption or metabolite formation half life; Cmax: peak plasma concentration; Tmax: time to the $\mathbf{C m a x}_{\mathbf{A}} \mathbf{A U C}_{\mathbf{0 - t}}$ : Area under the plasma concentration vs. time curve from 0 to the detection time; T1/2el: elimination half-life; $\mathbf{M R T}$ : mean residence time (obtained by non-compartmental analysis of the data). ${ }^{*}$ Significantly different from the FLBZ-CDs i.r. treated group at $\mathrm{P}<0.05$.

${ }^{1}$ Experiment 1: crossover design $(n=6)$ sheep were treated with the HPBCD-FLBZ solution (FLBZ-CDs) or the CMC-FLBZ suspension (FLBZ-CMC) by the i.r. route at the same dose rate $(3.8 \mathrm{mg} / \mathrm{kg})$.

${ }^{2}$ Experiment 2: intraabomasal (i.a.) administration of the FLBZ-CDs solution ( $\left.3.8 \mathrm{mg} / \mathrm{kg}, \mathrm{n}=4\right)$.

Figure 2 shows the mean concentration profiles for FLBZ (a) and R-FLBZ (b) in abomasal fluid, obtained after the i.r. administration of FLBZ as both formulations to sheep. The results of the kinetic analysis for these molecules in both experimental groups are summarized in Table 3. FLBZ and R-FLBZ were recovered in abomasal fluid after FLBZ administration as both formulations. Whereas the parent compound was found between 1 and $72 \mathrm{~h}$, the detection of R-FLBZ in abomasal fluid lasted up to $96 \mathrm{~h}$ post-treatment. The overall abomasal pharmacokinetic pattern for FLBZ and R-FLBZ was similar in both experimental groups, however a statistically difference in Cmax value $(\mathrm{P}<0.05)$ was observed for R-FLBZ.

The comparative plasma disposition kinetics of FLBZ (a) and R-FLBZ (b) observed after the i.r. and i.a. administration of the CDs-solution are shown in Figure 3. RFLBZ reached a peak concentration significantly earlier after the i.a. administration $(2.75 \pm 1.50 \mathrm{~h})$ compared to the i.r. treatment $(10.5 \pm 4.93 \mathrm{~h})$. On the other hand, the peak plasma concentration of the reduced metabolite resulted higher $(\mathrm{P}<0.05)$ after the i.a. administration $(0.35 \pm 0.09 \mu \mathrm{g} / \mathrm{mL})$, compared to that observed after the i.r. treatment $(0.23 \pm 0.04 \mu \mathrm{g} / \mathrm{mL})$. However, a faster plasma depletion either for FLBZ or R-FLBZ metabolite was observed in sheep treated by the i.a. route, this represented in both cases a lower AUC value $(\mathrm{P}<0.05)$ compared to that observed after the i.r. FLBZCDs administration $(1.35 \pm 0.34 \mu \mathrm{g} . \mathrm{h} / \mathrm{mL}$ and $6.82 \pm$ $1.77 \mu \mathrm{g} . \mathrm{h} / \mathrm{mL}$ for FLBZ and R-FLBZ, respectively).

\section{Discussion}

BZD methylcarbamate compounds are insoluble or slightly soluble in water. Solubility studies involving ABZ [22] or ABZSO [23] indicate that BZD methylcarbamate compounds possesses both acidic and basic groups in their chemical structure, with $\mathrm{pKa}$ values ranging between 7.2-10.7 and 2.4-4.7, respectively. Thus, the aqueous solubility of these compounds increases greatly when $\mathrm{pH}$ values are above 11 or below 2 . The impact of low $\mathrm{pH}$ values in improving the aqueous solubility of different BZD compounds has been previously demonstrated [24-26]. In the same direction, higher aqueous solubility of different BZD molecules was observed under our in vitro experimental conditions (Table 1). A markedly higher aqueous solubility at both, $\mathrm{pH} 1.2$ or 7.4, was obtained for ABZ, ABZSO, MBZ, OFZ and FLBZ. However, the highest solubility improvement was observed for FLBZ at $\mathrm{pH}$ 1.2, where the presence of HPßCD enhanced 70 fold its water solubility (Table 1 ).

FLBZ, R-FLBZ and H-FLBZ were recovered in plasma samples after i.r. administration of FLBZ formulated as either the CDs-solution or CMC-suspension. The active anthelmintic molecule after FLBZ treatment is the parent drug, which exhibits a high affinity binding for $B$ tubulin [5] and high potency in parasite motility test [27]. Additionally, the ovicidal activity against Fasciola hepatica eggs of the R-FLBZ metabolite has recently been described [28] as well as the in vitro activity against Echinococcus granulosus protoscoleces [29]. Additionally, this metabolite has demonstrated ability to accumulate (under ex vivo conditions) into target parasites equivalent to that observed for the parent FLBZ compound [4]. Consequently, a complementary effect of the parent drug and the reduced metabolite may account for the final anthelmintic activity after FLBZ administration.

The limited aqueous solubility of the most potent BZD compounds allows their formulation only as suspensions for oral administration to sheep. Water solubility and 

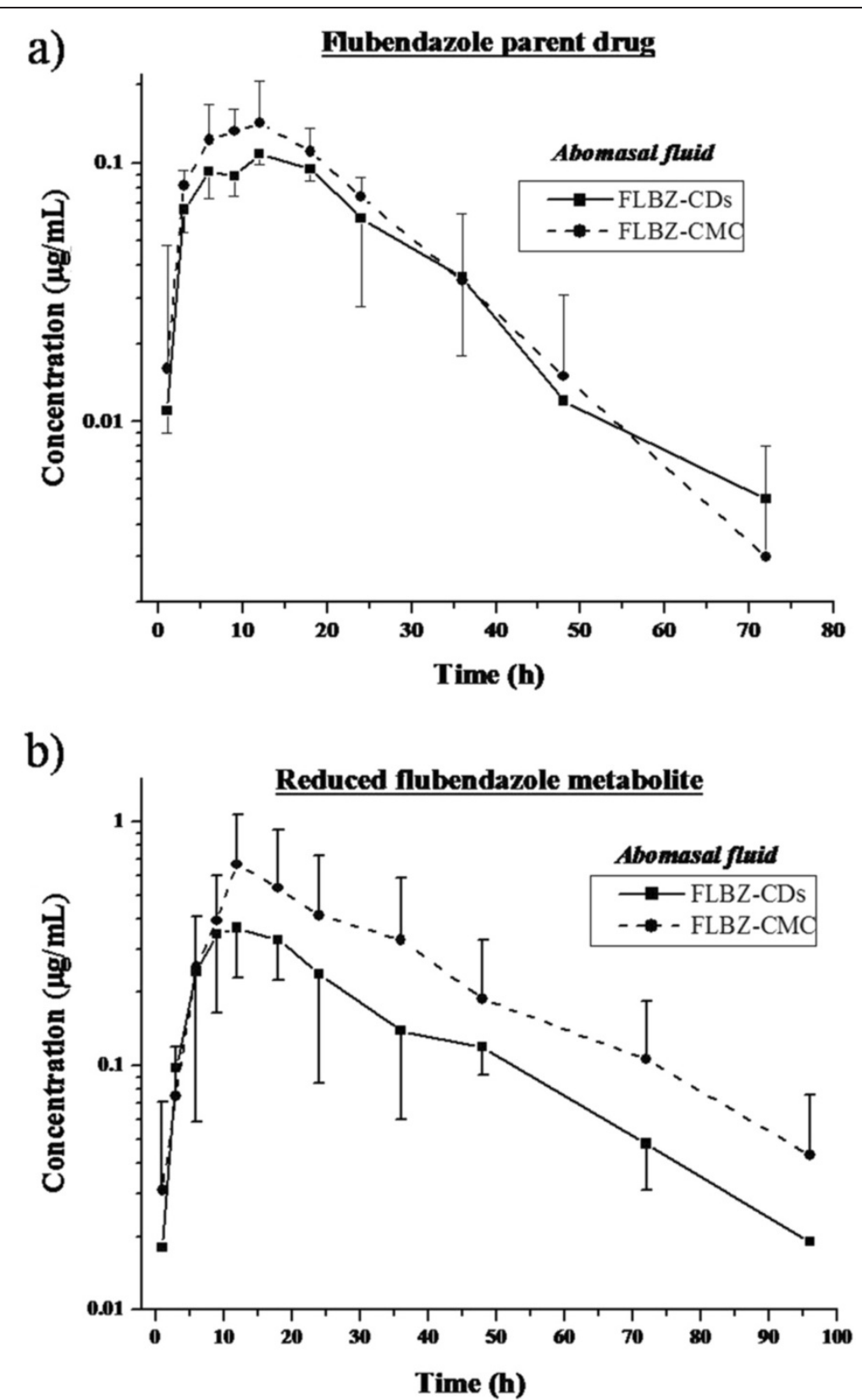

Figure 2 FLBZ/metabolites abomasal concentrations. Comparative mean $( \pm S D)$ abomasal fluid concentration profiles $(n=4)$ for a) flubendazole (FLBZ), and b) reduced flubendazole (R-FLBZ), after the intraruminal (i.r.) administration of FLBZ (3.8 mg/kg) as either, a cyclodextrin (CDs) solution or a carboxymethylcellulose (CMC) suspension to sheep.

the rate of dissolution in the gastrointestinal (GI) tract lumen have been shown to be relevant to the absorption and resultant systemic availability of BZD compounds in ruminants [6]. To increase the bioavailability of poorly soluble compounds, pharmaceutical scientists may rely on particle micronization, use of surfactant agents, or use of complexing agents such as CDs [7]. Increased ABZ aqueous solubility induced by HPßCD has previously been reported [30]. Moreover, the administration of an ABZ-HPßCD formulation to sheep increased GI absorption of ABZ with an increment (37\%) in the AUC value of the active ABZSO metabolite [18]. However, this formulation-based advantage in water solubility did not reach, under our experimental conditions, a beneficial pharmacokinetic result compared to the treatment with the FLBZ suspension. Contrarily to what was expected, the absorption-related pharmacokinetic parameters did not show any marked formulation-dependant effect. Only the Cmax value for the R-FLBZ metabolite was higher $(P<0.05)$ after administration of the novel 


\begin{tabular}{|c|c|c|c|c|}
\hline \multirow{2}{*}{$\begin{array}{l}\text { PHARMACOKINETIC } \\
\text { PARAMETERS }\end{array}$} & \multicolumn{2}{|c|}{ FLBZ } & \multicolumn{2}{|c|}{ R-FLBZ } \\
\hline & $\begin{array}{l}\text { FLBZ-CDs } \\
\text { i.r. treatment }\end{array}$ & $\begin{array}{l}\text { FLBZ-CMC } \\
\text { i.r. treatment }\end{array}$ & $\begin{array}{l}\text { FLBZ-CDs } \\
\text { i.r. treatment }\end{array}$ & $\begin{array}{l}\text { FLBZ-CMC } \\
\text { i.r. treatment }\end{array}$ \\
\hline $\mathrm{Cmax}(\mu \mathrm{g} / \mathrm{mL})$ & $0.11 \pm 0.01$ & $0.16 \pm 0.06$ & $0.43 \pm 0.13$ & $0.67 \pm 0.40^{*}$ \\
\hline $\operatorname{Tmax}(h)$ & $10.5 \pm 3.00$ & $9.75 \pm 2.87$ & $12.8 \pm 3.77$ & $12.0 \pm 0.00$ \\
\hline$A \cup C_{0-t}(\mu \mathrm{g} \cdot \mathrm{h} / \mathrm{mL})$ & $2.95 \pm 0.66$ & $3.63 \pm 1.05$ & $12.0 \pm 5.01$ & $21.7 \pm 15.8$ \\
\hline$T 1 / 2 \mathrm{el}(\mathrm{h})$ & $12.3 \pm 5.99$ & $9.83 \pm 4.23$ & $16.2 \pm 7.54$ & $16.3 \pm 5.95$ \\
\hline MRT (h) & $23.0 \pm 8.28$ & $20.4 \pm 5.23$ & $30.0 \pm 12.1$ & $31.2 \pm 8.80$ \\
\hline
\end{tabular}

T1/2abs/for: FLBZ absorption or metabolite formation half life; $\mathbf{C m a x}$ : peak plasma concentration; Tmax: time to the $\mathrm{Cmax}_{\mathbf{A}} \mathbf{A U C}_{\mathbf{0 - t}}$ : Area under the plasma concentration vs. time curve from 0 to the detection time; $\mathbf{T} 1 \mathbf{2} \mathbf{2}$ : : elimination half-life; MRT: mean residence time (obtained by non-compartmental analysis of the data). *Significantly different from the FLBZ-CDs i.r. treated group at $P<0.05$.

CD-based preparation $(0.23 \pm 0.04 \mu \mathrm{g} / \mathrm{mL})$ compared to that observed after the treatment with the CMCsuspension $(0.14 \pm 0.03 \mu \mathrm{g} / \mathrm{mL})$ (Table 2). The AUC values obtained after the administration of a CDs-based formulation resulted $73 \%$ (FLBZ) and 39\% (R-FLBZ) higher than those obtained for the CMC-based formulation. However, these differences did not reach statistical differences due to the large variation among experimental animals.

In mice treated with the FLBZ-HPßCD solution, the enhanced FLBZ absorption resulted in a significantly higher (>450\%) plasma Cmax compared to that obtained after the FLBZ-suspension treatment $(\mathrm{P}<0.05)$ [21]. This modified pharmacokinetic behaviour permitted a higher drug exposure of the hydatid cysts developed in mice, which enhanced the clinical efficacy of FLBZ in echinococcosis [21]. The drastic changes induced by CDs in the systemic availability of FLBZ in mice, do not correlate with the results observed in sheep. Chemical stability of numerous foreign compounds is affected by the microflora in the rumen (the first forestomach in ruminants). CDs are extensively metabolized in the human colon [15]. It is then likely that after the i.r. administration of the CD-FLBZ complex, a ruminal microflora-mediated metabolic process may have hydrolized/destroyed the CDs structure. This may facilitate FLBZ release into the ruminal fluid, which could then be associated to the particulate ruminal material as it occurs after the treatment with the suspension formulation. Such a phenomenon may account to explain the equivalent FLBZ systemic availability obtained following administration of two pharmaceutically well distinguish formulations. The absence of significant kinetic changes observed for FLBZ/metabolites in abomasal fluid after its administration as a CDs or CMC-formulation supports this argument.

To confirm the hypothesis of a CDs ruminal degradation, a pharmacokinetic study involving the i.a. administration of FLBZ as a CDs-based solution was performed. The plasma disposition kinetics of FLBZ/metabolites after its i.a. administration agrees with those reported after the i.a. administration of FBZ [31], OFZ [32] and ABZ [33] in sheep. Basically, the AUC and the Tmax of the parent compound were significantly $(\mathrm{P}<0.05)$ reduced by ruminal bypass. Furthermore, a significantly $(\mathrm{P}<0.05)$ shorter $\mathrm{T}^{1} / 2 \mathrm{abs}$ for FLBZ compared to the i.r. administration was observed (Table 2). Similar pharmacokinetic differences were observed for the R-FLBZ metabolite. When an orally administered BZD suspension reaches the rumen, an extensive adsorption of BZD molecules to the rumen particulate digesta has been shown to occur shortly after treatment [21]. This extensive association between drug molecules and the particulate material of the digesta does not inhibit absorption but delays the rate of passage of the drug down the GI tract. The rumen acts as a "drug reservoir" and prolongs the duration of drug absorption [21]. After the direct i.a. administration of a conventional BZD suspension, the drug formulation may bypass the rumen and the advantage of the "ruminal reservoir effect" is lost, resulting in poor dissolution of the BZD suspension in the abomasum due to a shorter residence time at the acidic abomasal $\mathrm{pH}$, which results in reduced intestinal absorption and lower systemic availability. After the i.a. administration of FLBZ as a HPßCD-based solution, we expected to observe an enhanced absorption and subsequent bioavailability of the parent compound. However, the CDs formulation behaved similar to the conventional suspension. The association (adsorption) of FLBZ with digestion particulate material could explain the lack of a clear effect on drug absorption induced by the novel formulation (FLBZ-CDs solution).

\section{Conclusions}

In conclusion the enhanced systemic availability FLBZ induced by CDs, did not reach a significant pharmacokinetic improvement, as it has been shown for monogastric species and does not seem to achieve a great practical relevance for use in parasite control in sheep. The work 

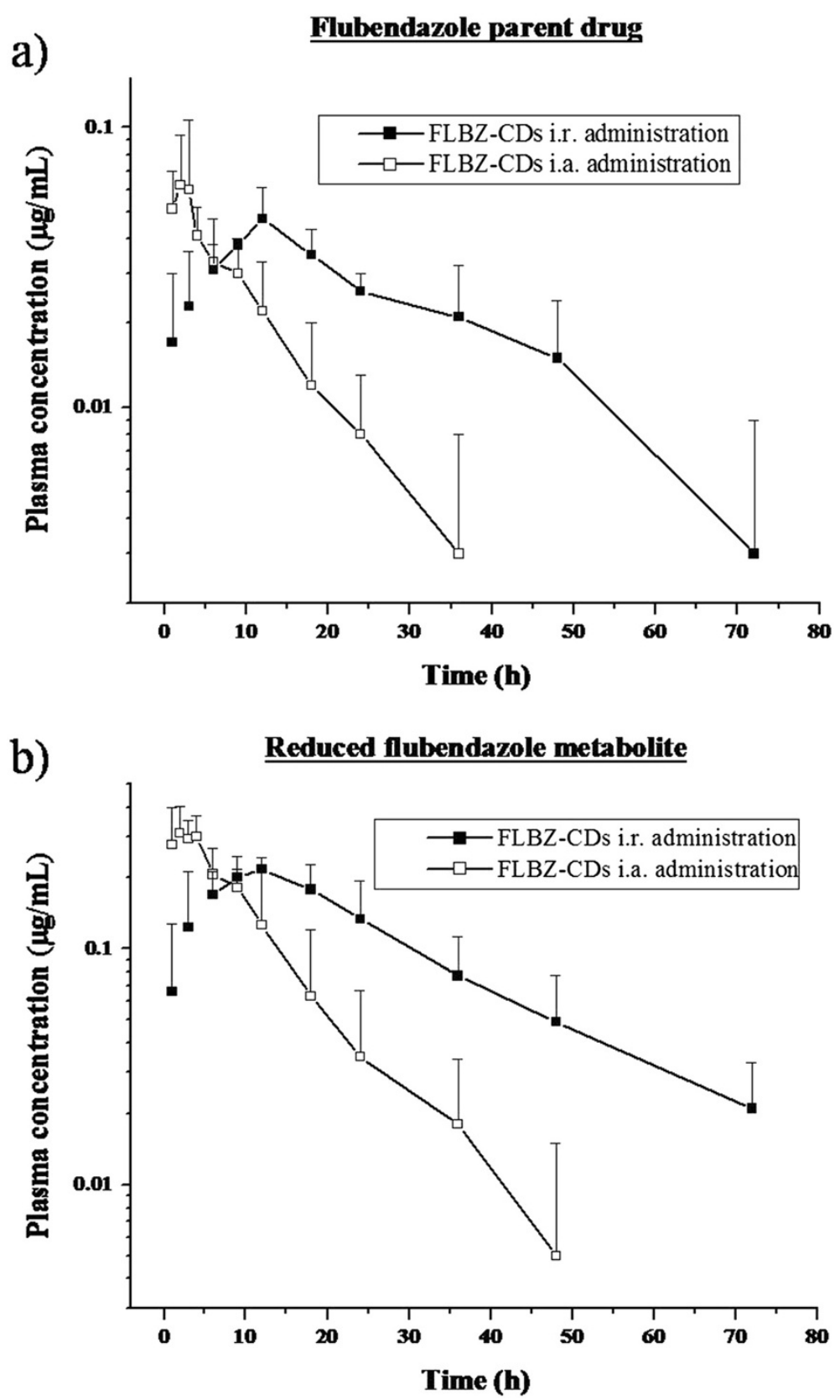

Figure 3 intraruminal vs intraabomasal plasma concentrations. Comparative mean $( \pm$ SD) plasma concentration profiles $(n=4)$ for a) flubendazole (FLBZ), and b) reduced flubendazole (R-FLBZ), after the intraruminal (i.r.) or intraabomasal (i.a.) administration of FLBZ (3.8 mg/kg) as a cyclodextrin (CDs) solution to sheep.

described here contributes with relevant information on the search of new and/or alternative pharmaceutical strategies to improve the systemic availability of well know anthelmintic drugs for use in ruminant species.

\section{Methods}

\section{Chemicals}

Pure reference standards of FLBZ, reduced-FLBZ (RFLBZ) and hydrolyzed-FLBZ (H-FLBZ) were kindly provided by Janssen Animal Health (Beerse, Belgium). Reference standards of oxibendazole (OBZ, used as internal standard), ABZ, albendazole sulphoxide (ABZSO) and mebendazole (MBZ) were obtained from Schering Plough (Kenilworth, NJ, USA), and oxfendazole (OFZ) from Rhone Merieux (Lyon, France). The solvents HPLC grade (acetonitrile and methanol) and Potassium phosphate (HPLC grade) were from Sintorgan S.A. (Buenos Aires, Argentina) and J.T. Baker (Phillipsburg, NJ, USA), 
respectively. Cargill Inc. (Hammond, IN, USA) kindly supplied us the HPßCD. CMC was purchased from Anedra (Buenos Aires, Argentina).

\section{In vitro dissolution study}

BZD solubilities were determined in aqueous solutions at $\mathrm{pH}$ values of $1.2(\mathrm{HCl} / \mathrm{KCl})$ and 7.4 $\left(\mathrm{KH}_{2} \mathrm{PO}_{4}\right)$ with or without $\mathrm{HP} ß C D(10 \%)$. An excess amount of $\mathrm{ABZ}$, ABZSO, MBZ, OFZ or FLBZ was suspended in glass tubes containing $10 \mathrm{~mL}$ of each medium. The tubes were placed in a water bath at $25^{\circ} \mathrm{C}$ with a constant shaken rate of 100 strokes/min for two weeks (Yamato BT-31, Yamato Scientific Co., Japan). Following equilibration, samples were centrifuged at $3000 \mathrm{x}$ g for $10 \mathrm{~min}$ (IEC CL 30R, Thermo Electro, Corporation, USA). The supernatants were collected and filtered through a $0.2 \mu \mathrm{m}$ filter (Whatman Inc., NJ, USA). After filtration, samples were analyzed for drug quantification by HPLC following the method described below.

\section{In vivo pharmacokinetic study FLBZ formulations}

FLBZ-solution $(2 \% \mathrm{w} / \mathrm{v})$ was prepared by dissolution of $2 \mathrm{~g}$ of pure FLBZ and $10 \mathrm{~g}$ of HPßCD in $100 \mathrm{~mL}$ of dionized water ( $\mathrm{pH}$ 1.2). The $\mathrm{pH}$ was adjusted using hydrochloric acid $(25 \mathrm{mM})$. The formulation was shaken during $48 \mathrm{~h}\left(40^{\circ} \mathrm{C}\right)$ and then was filtrated through a $0.45 \mu \mathrm{m}$ filter (Whatman, NJ, USA). The final FLBZ concentration was confirmed by HPLC $(n=4)$. The FLBZ suspension $(2 \% \mathrm{w} / \mathrm{v})$ was performed by addition of $2 \mathrm{~g}$ FLBZ pure standard in a suspension of CMC $(0.5 \% \mathrm{w} / \mathrm{v})$ prepared with deionized water $(100 \mathrm{~mL}, \mathrm{pH}=6.0)$ under shaking $(24 \mathrm{~h})$. The FLBZ suspension was vigorously shaken before its administration to sheep.

\section{Experimental animals}

Six (6) parasite-free Corriedale male sheep (average weight: $50.6 \pm 6.0 \mathrm{~kg}$ ) were used in this experiment. Animals were kept indoors with commercial balanced food and water ad libitum for two months prior and during the trial. Four (4) animals were surgically fitted with a permanent cannula in the pyloric region of the abomasum following an adaptation of the technique described by Komarek [34]. A 6-week post-surgery recovery period was allowed before starting the pharmacokinetic trials. Animal procedures and management protocols were approved by the Ethics Committee according to the Animal Welfare Policy (act 087/02) of the Faculty of Veterinary Medicine, Universidad Nacional del Centro de la Provincia de Buenos Aires (UNCPBA), Tandil, Argentina (http://www.vet.unicen.edu.ar).

\section{Experimental design, treatments and sampling Experiment 1: Intraruminal treatment}

The experiment was conducted following a crossover design with two different experimental phases. In phase I, sheep were treated with the HPBCD-FLBZ solution (FLBZ-CDs Group, $\mathrm{n}=3$ ) or the CMC-FLBZ suspension (FLBZ-CMC Group, $\mathrm{n}=3$ ) by the i.r. route at the same dose rate $(3.8 \mathrm{mg} / \mathrm{kg})$. Intraruminal administration was accomplished by injecting the FLBZ formulation (CDsor CMC-based) into the rumen through the body wall of the left paralumbar fossa using a $16 \mathrm{Gx} 1 \frac{1}{2} 2$ inch needle. Two animals in each group had a cannula fitted in the abomasum. The treatment groups were reversed after a 21-days washout period. Blood and abomasal fluid samples were collected prior to treatment and at $1,3,6,9$, $12,18,24,36,48,72$ and $96 \mathrm{~h}$ post-treatment. Immediately after collection, plasma was separated by centrifugation at $3000 \mathrm{x}$ g for 15 minutes. Plasma and abomasal fluid samples were placed into plastic vial and stored at $-20^{\circ} \mathrm{C}$ until analyzed.

\section{Experiment 2: Intraabomasal treatment}

Based on the results obtained after the i.r. treatment, a complementary experiment with intraabomasal (i.a.) administration of the FLBZ-CDs solution was performed. The i.a. administration of the HP $\beta C D$-FLBZ solution was done by direct injection of the formulation through the intra-abomasal cannulae avoiding liquid losses, at $3.8 \mathrm{mg} / \mathrm{kg}$. Blood samples were obtained prior to treatment and at $1,2,3,4,6,9,12,18,24,36,48$ and $72 \mathrm{~h}$ post-treatment. The recovered plasma was stored at $-20^{\circ} \mathrm{C}$ until analyzed.

\section{Plasma samples extraction}

Plasma and abomasal fluid samples $(1 \mathrm{~mL})$ were spiked with $20 \mu \mathrm{L}$ of OBZ (stock solution $50 \mu \mathrm{g} / \mathrm{mL}$ ) as internal standard. FLBZ and its metabolites were extracted using disposable cartridges (Strata ${ }^{\circledR}$, Phenomenex, CA, USA) previously conditioned with $0.5 \mathrm{~mL}$ of methanol, followed by $0.5 \mathrm{~mL}$ of water, as previously described by Moreno et al. [4]. All samples were injected into cartridges and then sequentially washed with $1.5 \mathrm{~mL}$ of water and eluted with $2 \mathrm{~mL}$ of methanol. For abomasal fluid samples there was a further extraction step using ethyl acetate before $\mathrm{C} 18$ cartridge extraction, as reported by Lanusse et al. [35]. In both cases (plasma and abomsasal fluid samples), the elutant was evaporated to dryness in a vacuum concentrator (Speed-Vac ${ }^{\circledR}$, Savant, $\mathrm{CE}$ ), then reconstituted with $200 \mu \mathrm{L}$ of the same mobile phase used on the HPLC system. Additionally, a calibration curve was performed by mean of spiked plasma/abomasal fluid with known concentrations of pure standards of FLBZ/ metabolites (fortified samples). Experimental and fortified 
samples were analyzed for FLBZ, R-FLBZ and H-FLBZ, and the internal standard by HPLC.

\section{HPLC analysis}

Experimental and fortified samples of plasma and abomasal fluid were analyzed for FLBZ, R-FLBZ, H-FLBZ and the internal standard (OBZ) by HPLC following the method described by Moreno et al. [4]. Briefly, $50 \mu \mathrm{L}$ of sample were injected in a Shimadzu 10 A HPLC System (Kyoto, Japan), using an UV detector set at $292 \mathrm{~nm}$, an autosampler and a controller (Shimadzu Class LC10, Kyoto, Japan). Elution from the stationary phase (Selectosil $\mathrm{C}_{18}$ column, $5 \mu \mathrm{m}, 250 \times 4.6 \mathrm{~mm}$, Phenomenex ${ }^{\circledR}, \mathrm{CA}$, USA) has been carried out at a flow rate of $1.2 \mathrm{~mL} / \mathrm{min}$, using a mixture of acetonitrile:potassium phosphate buffer $(25 \mathrm{mM}, \mathrm{pH}$ 5.3) (40:60) as a mobile phase, during $13 \mathrm{~min}$ at $30^{\circ} \mathrm{C}$.

The calibration curves for each analyte constructed by least squares linear regression analysis, showed good linearity with correlation coefficients greater than 0.993 . Recovery of the three molecules under study was estimated by comparison of the peak areas from spiked plasma/abomasal fluid, resulting from direct injections of standards in mobile phase. The absolute recovery for FLBZ, R-FLBZ and H-FLBZ ranged between 73 and $94 \%$ with coefficients of variation $(\mathrm{CV}) \leq 9 \%$. The limit of quantification (LOQ) was defined as the lowest measured concentration with a percentages of residual standard deviation (\%RSD) $<20 \%$, an accuracy of $\pm 20 \%$ (measured as percentage of relative error) and an absolute recovery $\geq 70 \%$. The LOQ obtained for the assayed molecules was 0.01 (plasma) and 0.05 (abomasal fluid) $\mu \mathrm{g} / \mathrm{mL}$. Values below LOQ were not included in the pharmacokinetic analysis.

\section{Pharmacokinetic analysis of the data}

The concentration vs time curves for FLBZ and/or its metabolites in plasma for each individual animal were fitted with the PKSolutions ${ }^{\mathrm{TM}}$ computer program (Summit Research Service, OH, USA). The following equation [36] was used to describe the biexponential concentration-time curves for FLBZ and R-FLBZ after the i.r./i.a treatments:

$$
C p=B e^{-\beta t}-B e^{-k t}
$$

where $\mathrm{Cp}=$ concentration $(\mu \mathrm{g} / \mathrm{mL})$ in plasma at time $t$ after administration; $\mathrm{B}=$ concentration at time zero extrapolated from the elimination phase $(\mu \mathrm{g} / \mathrm{mL}) ; e=$ base of the natural logarithm; $\beta=$ terminal slope $(/ \mathrm{h})$; and $k$ is the slope determined by feathering which represents either the first-order absorption rate constant $\left(k_{a b}\right)$ or first-order metabolite formation rate constant $\left(k_{f p r}\right)$ $(/ \mathrm{h})$. The elimination half life $\left(\mathrm{T}^{1} / 2 \mathrm{el}\right)$ and absorption
$\left(\mathrm{T}^{1} 12 \mathrm{ab}\right)$ or metabolite formation ( $\mathrm{T}^{1} \frac{1}{2}$ for) half lives were calculated as $\ln 2 / \beta$ and $\ln 2 / k$, respectively. The peak concentration (Cmax) and time to peak concentration (Tmax) were read from the plotted concentration-time curve of each analyte. The area under the concentration-time curve (AUC) was calculated by the trapezoidal rule [37]. Statistical moment theory was applied to calculate the mean residence time of FLBZ and R-FLBZ in plasma and abomasal fluid samples as follow:

$$
\mathrm{MRY}=\mathrm{AUMC} / \mathrm{AUC}
$$

where AUC is defined previously and AUMC is the area under the curve of the product of time and the plasma drug concentration vs time from 0 to $\infty$ [37].

\section{Statistical analysis of the data}

The in vitro aqueous solubility values are presented as arithmetic mean \pm SD. Student's t-test was used to compare BZD water solubility values, obtained with or without HPßCD, and at two different pHs (1.2 or 7.4). The pharmacokinetic parameters and concentration data are also reported as arithmetic mean \pm SD. Statistical comparison of mean pharmacokinetic parameters for FLBZ/ metabolites administered by the i.r. route as a HPßCDbased solution or suspension (Experiment 1) was performed using Student's t-test for paired observations (plasma samples) or Mann-Whitney non parametric test (abomasal fluid samples). The comparison of the plasma and abomasal fluid pharmacokinetic parameters obtained for FLBZ/metabolites after the i.r. or i.a. (Experiment 2) administration was performed by non parametric test (Mann-Whitney test). In all cases, a value of $\mathrm{P}<0.05$ was considered statistically significant. The statistical analysis was performed using the Instat 3.0 Software (Graph Pad Software, CA, USA).

\section{Competing interests}

The authors declare that they have no competing interests.

\section{Authors' contributions}

LC, LM and LA participate in the animal and analytical phase of the in vivo experiments and in writing the draft manuscript. JT carried out the in vitro experiment. $\mathrm{LA}$ and $\mathrm{CL}$ conceived the study, participated in its design and in the animal phase, and revised the draft version of the manuscript. All authors have read and approved the final manuscript.

\section{Acknowledgements \\ We gratefully acknowledge the financial supported by Fundación Bunge y Born, Argentina. The authors acknowledge Dr. Leo Van Leemput, Dr. Kathleen Vlaminck (Janssen Animal Health, Beerse, Belgium) and Dr. Gustavo Viana (Janssen, BsAs, Argentina) for providing FLBZ/metabolites used in the present experimental work. The HPßCD was kindly supply by Cargill Inc. (Hammond, IN, USA).}

\section{Author details}

'Departamento de Fisiopatología, Laboratorio de Farmacología, Facultad de Ciencias Veterinarias, Universidad Nacional del Centro de la Provincia de Buenos Aires (UNCPBA), Campus Universitario, 7000 Tandil, Argentina. ${ }^{2}$ Consejo Nacional de Investigaciones Científicas y Técnicas (CONICET), Tandil, 
Argentina. ${ }^{3}$ Departamento de Farmacia y Tecnología Farmacéutica, Facultad de Farmacia, Universidad Complutense de Madrid, Madrid, Spain.

Received: 22 November 2011 Accepted: 17 April 2012

Published: 28 May 2012

\section{References}

1. EMEA, EMEA/MRL/267/97-FINAL: The European Agency for the Evaluation of Medicinal Products. Flubendazol, Summary Report 2; Veterinary Medicines Evaluation Unit. London, UK: Committee for Veterinary Medicinal Products; 1997.

2. Gottschall D, Theodorides V, Wang R: The metabolism of benzimidazole anthelmintics. Parasitol Today 1990, 6:115-124.

3. Maté L, Virkel G, Lifschitz A, Ballent M, Lanusse C: Hepatic and extrahepatic metabolic pathways involved in flubendazole biotransformation in sheep. Biochem Pharmacol 2008, 76:773-783.

4. Moreno L, Alvarez L, Mottier L, Virkel G, Sanchéz Bruni S, Lanusse C: Integrated pharmacological assessment of flubendazole potential for use in sheep: disposition kinetics, liver metabolism and parasite difusión ability. J Vet Pharmacol Therap 2004, 27:299-308.

5. Lacey E: Mode of action of benzimidazoles. Parasitol Today 1990, 6:112-115.

6. Lanusse C, Prichard R: Clinical pharmacokinetics and metabolism of benzimidazole anthelmintics in ruminants. D Metab Rev 1993, 25:235-279.

7. Alvarez L, Mottier L, Lanusse C: Drug transfer into target helminth parasites. Trends Parasitol 2007, 23:97-104.

8. Moreno L. Echevarria F, Muñoz F, Alvarez L, Sánchez S, Lanusse C: Dosedependent activity of albendazole against benzimidazole-resistant nematodes in sheep: relationship between pharmacokinetics and efficacy. Exp Parasitol 2004, 106:150-157.

9. Sanchez Bruni S, Fuse L, Moreno L, Saumell C, Alvarez L, Fiel C, McKellar Q, Lanusse C: Changes to oxfendazole chiral kinetics and anthelmintic efficacy induced by piperonyl butoxide in horses. Equine Vet J 2005, 37:257-262.

10. Entrocasso C, Alvarez L, Manazza J, Lifschitz A, Borda B, Virkel G, Mottier L, Lanusse C: Clinical efficacy assessment of the albendazole-ivermectin combination in lambs parasitized with resistant nematodes. Vet Parasitol 2008, 155:249-256

11. Frömming K, Szejtli J: Cyclodextrins in pharmacy. Dordrecht: Kluwe Academic Publishers; 1994:27-29.

12. Loftsson T, Duchêne D: Cyclodextrins and their pharmaceutical applications. Int J Pharm 2007, 329:1-11.

13. Rajewski R, Stella V: Pharmaceutical applications of cyclodextrins 2. In vivo drug delivery. J Pharm Sci 1996, 85:1142-1169.

14. Diaz D, Bernad M, Gracia Mora J, Escobar Llanos C: Complexation and solubility behavior of albendazole with some cyclodextrins. Pharm Dev Technol 1998, 3:395-403.

15. Challa R, Ahuja A, Ali J, Khar R: Cyclodextrins in Drug Delivery: An Updated Review. AAPS PharmSciTech 2005, 6:329-357.

16. Martins P, Ochoa R, Pimenta A, Ferreira L, Melo A, Da Silva J, Sinisterra R, Demicheli $C$, Frezard F: Mode of action of $\beta$-cyclodextrin as an absorption enhancer of the water-soluble drug meglumine antimoniate. Int J Pharm 2006, 325:39-47.

17. Martinez M, Augsburgerb L, Johnstonc T, Jones W: Applying the Biopharmaceutics Classification System to veterinary pharmaceutical products. Part I: Biopharmaceutics and formulation considerations. Adv Drug Deliv Ver 2002, 54:805-824.

18. Evrard B, Chiap P, DeTullio P, Ghalmid F, Piela G, Van Heesa T, Crommen J, Losson B, Delattre L: Oral bioavailability in sheep of albendazole from a suspension and from a solution containing hydroxypropyl- $\beta$ cyclodextrin. J Control Release 2002, 85:45-50.

19. García Rodriguez J, Torrado J, Bolas F: Improving bioavailability and anthelmintic activity of albendazole by preparing albendazolecyclodextrin complexes. Parasite 2001, 8:188-190.

20. Casulli A, Morales M, Gallinilla B, Turchetto L, Pozio E: 2-Hydroxypropylbeta-cyclodextrin improves the effectiveness of albendazole against encapsulated larvae of Trichinella spiralis in a murine model. J Antimicrob Chemother 2006, 58:886-890.

21. Ceballos L, Elissondo M, Sánchez Bruni S, Denegri G, Alvarez L, Lanusse C: Flubendazole in cystic echinococcosis therapy: pharmaco-parasitological evaluation in mice. Parasitol Int 2009, 58:354-358.
22. Jung H, Medina L, García L, Fuentes I, Moreno-Esparza R: Absorption studies of albendazole and some physicochemical properties of the drug and its metabolite albendazole sulphoxide. J Pharm Pharmacol 1997, 50:43-48.

23. Wu Z, Razzak M, Tucker I, Medlicott N: Physicochemical characterization of ricoendazole: I. Solubility, lipophilicity, and ionization characteristics. J Pharm Sci 2005, 94:983-993.

24. Marriner S, Evans E, Bogan J: Effect of parasitism with Ostertagia circumcincta on pharmacokinetics of fenbendazole in sheep. Vet Parasitol 1985, 17:239-249.

25. McKellar Q, Scott E: The benzimidazole anthelmintic agents- a review. J Vet Pharmacol Therap 1990, 27:299-308.

26. Sánchez S, Alvarez L, Pis A, Quiroga M, Lanusse C: Differences on the plasma and abomasal disposition of albendazole and its metabolites in calves grazing on pasture or fed a concentrate diet. Res Vet Sci 1999, 66:223-230

27. Petersen $\mathrm{M}$, Friis $\mathrm{C}$, Bjorn $\mathrm{H}$ : A new in vitro assay of benzimidazole activity against adult Oesophagostomum dentatum. Int J Parasitol 1997, 27:1333-1339.

28. Alvarez L, Moreno G, Moreno L, Ceballos L, Shaw L, Fairweather I, Lanusse C: Comparative assessment of albendazole and triclabendazole ovicidal activity on Fasciola hepatica eggs. Vet Parasitol 2009, 164:211-216.

29. Ceballos L, Alvarez L, Sanchez Bruni S, Elissondo C, Denegri G, Lanusse C: Comparative performances of flubendazole and albendazole in cystc echinococcosis. Ex vivo activity, plasma/cyst disposition, and efficacy in infected mice. Antimicrob Agents Chemother, in press. Published abstract.

30. Castillo J, Palomo-Canales J, García J, Lastres J, Bolas F, Torrado J: Preparation and characterization of albendazole beta-cyclodextrin complexes. Drug Dev Ind Pharm 1999, 25:1241-1248.

31. Marriner S, Bogan J: Pharmacokinetic of fenbendazole in sheep. Am J Vet Res 1981, 42:1146-1148.

32. Prichard R, Hennessy D: Effects of oesophageal groove closure on the pharmacokinetic behaviour and efficacy of oxfendazole in sheep. Res Vet Sci 1981, 30:22-27.

33. Alvarez L, Sánchez S, Lanusse C: Plasma and abomasal bioavailability of albendazole administered by different routes to sheep. J Vet Pharmacol Therap 1997, 20:70-71.

34. Komarek R: Rumen and abomasal cannulation of sheep with specially designed cannulae and a canula insertion instrument. J Anim Sci 1981, 53:791-795.

35. Lanusse C, Gascon L, Prichard R: Gastrointestinal distribution of albendazole metabolites following netobimin administration to cattle: relationship with plasma disposition kinetics. J Vet Pharmacol Therap 1993, 16:38-47.

36. Notari R: Biopharmaceutics and Clinical Pharmacokinetics. New York: Marcel Dekker: 1987:45-129.

37. Gibaldi M, Perrier D: Pharmacokinetics. New York: Marcel Dekker;1982:p45109.

doi:10.1186/1746-6148-8-71

Cite this article as: Ceballos et al:: Exploring flubendazole formulations for use in sheep. Pharmacokinetic evaluation of a cyclodextrin-based solution. BMC Veterinary Research 2012 8:71.

\section{Submit your next manuscript to BioMed Central and take full advantage of:}

- Convenient online submission

- Thorough peer review

- No space constraints or color figure charges

- Immediate publication on acceptance

- Inclusion in PubMed, CAS, Scopus and Google Scholar

- Research which is freely available for redistribution 